\title{
QUALIDADE DE VIDA, PERFIL DEMOGRÁFICO E PROFISSIONAL DE PROFESSORES DE EDUCAÇÃO FÍSICA
}

\author{
Junior Vagner Pereira da Silva \\ Universidade para o Desenvolvimento do Estado e da Região do Pantanal, Campo Grande, \\ Mato Grosso do Sul, Brasil.

\section{Paulo Ricardo Martins Nunez} \\ Universidade para o Desenvolvimento do Estado e da Região do Pantanal, Campo Grande, \\ Mato Grosso do Sul, Brasil.
}

\begin{abstract}
Resumo
Este estudo objetivou identificar o perfil demográfico e profissional de professores de Educação Física, bem como a associação entre o nível de qualidade de vida e a idade, o tempo de docência e a carga horária semanal de trabalho. Foram avaliados 69 professores de Educação Física de escolas públicas em Campo Grande - MS. Na qualidade de vida geral, a amostra obteve 74,4 pontos, indicando uma boa qualidade de vida. $\mathrm{Na}$ análise por domínios, o social $(75,24 \%)$ figurou como o mais positivo e o físico $(58,75$ pontos $)$ o mais prejudicado. O salário foi apontado por $66,7 \%$ como o principal fator de insatisfação profissional. No teste de relação entre as variáveis, nenhuma associação estatisticamente significante foi encontrada. Conclui-se que a maioria dos professores classificou sua qualidade de vida como "boa" e que o perfil demográfico e profissional não exerceu influência sobre a qualidade de vida.

Palavras-chave: Trabalho - Qualidade de vida - Docente.
\end{abstract}

\section{Introdução}

Wos últimos anos, a sociedade tem passado por grandes transformações políti1 cas, sociais, econômicas e tecnológicas e, embora essas transformações tenham trazido significativos benefícios ao desenvolvimento econômico e social, em alguns casos têm atuado de forma negativa, pois viver nessa sociedade de forma realizadora, criativa e relativamente independente é uma tarefa árdua e, muitas vezes, difícil de ser realizada, haja vista que o bem estar físico e mental são deixados de lado para que as necessidades básicas sejam supridas.

A vida moderna e as exigências no âmbito do trabalho levam os indivíduos a, gradativamente, desenvolver algum tipo de distúrbio, uma vez que as atribuições diárias, a má alimentação, a falta de tempo para o lazer, o pouco tempo para o descanso e o sono, acabam resultando em má qualidade de vida e, conseqüentemente, em estresse (MELEIRO, 2002). Em parte isso tem ocorrido devido à qualidade de vida do trabalhador não estar dentre as prioridades das organizações, uma vez que, ao invés de procurarem aumentar a capacidade das pessoas de ascenderem e realizarem conquistas, estão fazendo com que um maior número de trabalhadores sacrifique sua vida e pretensões pelo bem estar das empresas (MASLACH; LEITER, 1999). 
No caso dos professores, essa situação pode agravar-se ainda mais porque eles acumulam inúmeras funções - como as de amigo, confidente, pai e mãe - e necessitam, com isso, adequar-se e conhecer individualmente cada aluno (TRICOLLI, 1997). Além disso, as condições de trabalho não têm sido as melhores, pois, de acordo com Nunes Sobrinho (2002), o professor em sua prática pedagógica ainda tem de se adequar a condições de ensino adversas. Dentre os aspectos causadores de estresse no magistério, o autor destaca a incompatibilidade entre os limites pessoais do professor diante da demanda da população infantil e do sistema educacional (comportamento do aluno, design do mobiliário escolar, iluminação das salas de aula, o nível de ruído, a temperatura ambiente, excesso de trabalho extraclasse, relacionamento entre professores, falta de capacitação, indisciplina dos alunos, falta de condições para exercer o magistério, má formação profissional e falta de apoio dos diretores). Para Salim (2004), capacitação, salário, tempo de docência, condições de trabalho (estrutura física e quantidade de alunos), são fatores que podem exercer grande influência no estado emocional desses profissionais.

Ante as exigências cotidianas e as metas a serem atingidas num período curto, entre outros, os professores não têm tempo para cuidarem de si próprios e são levados a enfrentar situações estressantes no seu cotidiano escolar, que podem, em longo prazo, interferir sobre a sua saúde geral (MOLINA, 1996).

No que se refere ao professor de Educação Física, há de se considerar, ainda, que, em sua maioria, ficam expostos a outras condições estressantes - tais como luz do sol, poeira e ruídos ambientais -, pois nem todas as escolas possuem, por exemplo, quadras cobertas.

Diante do exposto, este estudo teve como objetivo identificar o perfil demográfico e profissional de professores de Educação Física bem como correlacionar o nível de qualidade de vida com a idade, o tempo de docência e a carga horária semanal de trabalho desses profissionais.

\section{Métodos}

A pesquisa foi de caráter exploratório, que possibilita a descoberta de práticas que precisam ser modificadas e a elaboração de alternativas substitutivas (OLIVEIRA, 2002).

A população do estudo foi professores de Educação Física da Rede Municipal de Ensino de Campo Grande - MS, tendo como amostra 69 professores, de ambos os sexos, selecionados por meio do método aleatório simples (THOMAS; NELSON, 2002).

A coleta de dados procedeu-se pela técnica de aplicação de questionário (MARCONI; LAKATOS, 2002). Como instrumento de avaliação do perfil demográfico e profissional foi utilizado um questionário elaborado especificamente para este fim, sendo estruturado com questões fechadas. Na análise da qualidade de vida recorreu-se ao questionário Whoqol-bref, criado pela Organização Mundial da Saúde - OMS, em 1998 (THE WHOQOL GROUP, 1998), traduzido e validado à realidade brasileira por Fleck et al. (2000). O Whoqol-bref é composto por 26 questões, sendo 24 referentes aos quatro domínios (físico, psicológico, social e meio ambiente) e duas sobre a qualidade de vida em geral (FLECK et al., 2000). 
No tratamento dos dados recorreu-se à planilha do programa Excel, utilizando a análise de frequência e média para as variáveis referentes ao perfil profissional e à sintaxe proposta por The Whoqol Group (1998) para computar as pontuações para a qualidade de vida.

A relação entre idade, tempo de docência e a carga horária semanal de trabalho com a qualidade de vida foi avaliada por meio da aplicação do teste de correlação de Pearson (r).

\section{Resultados e discussão}

Os dados do perfil demográfico revelaram que a média de idade dos professores é de 35,5 $\pm 8,4$ anos, tendo o mais novo 22 anos e o mais velho 57 . Dentre eles, 59,4\% eram casados e $40,6 \%$ solteiros. Dados semelhantes foram encontrados por Lemos (2007) que avaliou docentes da área de Educação Física e por Penteado e BicudoPereira (2007) que estudaram professores do Ensino Médio de diversas disciplinas. No que se refere ao gênero, os resultados obtidos indicaram predominância do sexo masculino $(60,9 \%)$ em relação ao feminino $(39,1)$.

Em relação à carga horária semanal de trabalho (Tabela 1), a maioria dos professores trabalhava por mais de 20 horas, o que corresponde basicamente a dois períodos de aulas. Estudos desenvolvidos por Lemos, Nascimento e Both (2006), Lemos (2007), Penteado e Bicudo-Pereira (2007) e Farias et al. (2008), constataram dados semelhantes.

Tabela 1 - Distribuição dos professores quanto à carga horária semanal de trabalho

\begin{tabular}{|l|c|}
\hline \multicolumn{1}{|c|}{ Número de horas/aulas por semana } & $\%$ \\
\hline Até 10 horas & $1,4 \%$ \\
\hline De 11 a 20 horas & $27,5 \%$ \\
\hline De 21 a 30 horas & $11,6 \%$ \\
\hline De 31 a 40 horas & $43,5 \%$ \\
\hline De 41 a 50 horas & $7,2 \%$ \\
\hline De 51 a 60 horas & $8,7 \%$ \\
\hline
\end{tabular}

A maior insatisfação dos professores está relacionada à remuneração salarial, conforme pode ser observado na Tabela 2 . A remuneração salarial também foi apontada como o principal motivo de insatisfação entre docentes investigados em outros estudos brasileiros (LAPO, 2000; PETROSKI, 2005; LEGNANI et al., 2005; ROMANZINI et al., 2005; LEMOS; NASCIMENTO; BOTH, 2006; LEMOS, 2007; PENTEADO; BICUDO-PEREIRA, 2007; FOLLE et al., 2008; BOTH; NASCIMENTO; BORGATTO, 2008).

Tabela 2 - Fatores de insatisfação dos professores

\begin{tabular}{|l|c|}
\hline \multicolumn{1}{|c|}{ Fatores de insatisfação } & Percentual \\
\hline Salário & $66,7 \%$ \\
\hline Número de alunos por sala & $31,9 \%$ \\
\hline Condições de trabalho & $11,6 \%$ \\
\hline Cobranças da direção & $10,1 \%$ \\
\hline Relação com os alunos & $8,7 \%$ \\
\hline Relação com os colegas & $4,3 \%$ \\
\hline
\end{tabular}


Mesmo com o salário sendo apontado como principal fator de insatisfação, é preciso considerar que o número de alunos por sala, as condições de trabalho (materiais e equipamentos) e as cobranças da direção também foram citados pelos professores. Estudos desenvolvidos por Petroski (2005), Lemos, Nascimento e Both (2006), Penteado e Bicudo-Pereira (2007) e Lemos (2007) também constataram que as condições de trabalho ocasionavam insatisfação entre os professores.

A insatisfação com a remuneração obtida no emprego pode estar fazendo com que parte dos professores busque meios de aumentar sua renda familiar envolvendose com outras atividades, haja vista que o "pluriemprego" foi constatado em 37,7\%. Dos que realizam outro tipo de atividade além da docência no âmbito escolar, 61,53\% complementavam o rendimento com atividades relacionadas á área de formação (aulas de musculação, hidroginástica, lutas, iniciação esportiva, preparação física e ginástica para terceira idade) e 38,46\% com atividades não relacionadas (administração rural, reciclagem, vendedor, artesão, instrutor de informática, músico, telefonista e autônomo). Lemos, Nascimento e Both (2006) e Farias et al. (2008) observaram percentuais bem mais elevados de "pluriemprego" entre docentes de Educação Física, respectivamente $68,6 \%$ e $56,3 \%$.

$\mathrm{Na}$ avaliação da qualidade de vida geral, obtida através da questão 1 do Whoqolbref (Como você avalia a sua qualidade de vida?), a média das respostas apresentou um escore de 74,4 pontos. Esse resultado indica que o grupo classificara sua qualidade de vida como "boa".

O bom nível de qualidade de vida dos professores é confirmado quando os dados são submetidos à análise de frequência. Conforme pode ser observado na Figura 1, $56,5 \%$ classificaram sua qualidade de vida como "boa" e 11,6\% como "muito boa".

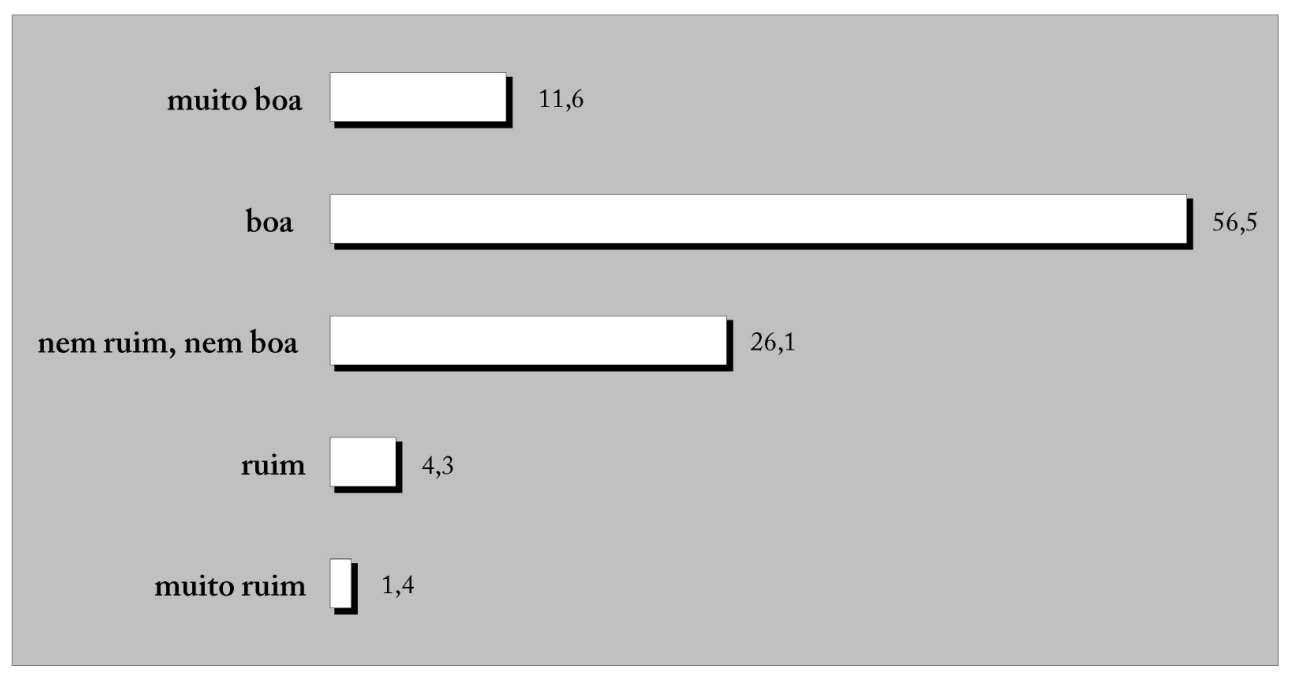

Figura 1 - Análise de frequência (\%) da classificação da qualidade de vida dos professores de Educação Física da Rede Municipal de Ensino de Campo Grande - MS.

Estudo realizado por Penteado e Bicudo-Pereira (2007), com 128 professores da rede pública de Rio Claro - SP, constatou um valor médio de 66 pontos. Ainda, 65,6\% classificaram sua qualidade de vida como "boa". 
Segundo Fernandes (1996), a boa qualidade de vida no trabalho exerce grande influência sobre a autoestima do trabalhador, podendo, consequentemente, afetar sua produtividade. No entanto, na classe docente, a importância da qualidade de vida vai além da produtividade, considerando que o professor influencia sobremaneira a formação moral e as atitudes de seus alunos - muitas vezes servindo de referência: é possível que um professor agressivo tenha como resposta um grupo de alunos agressivos, da mesma forma que um professor paciente e calmo poderá ter uma resposta igual de seus alunos (TRICOLLI, 1997).

Analisando os resultados por domínios, constatou-se que o domínio físico e o meio ambiente configuraram-se como os de menor nível de qualidade de vida, conforme pontuação apresentada na Figura 2.

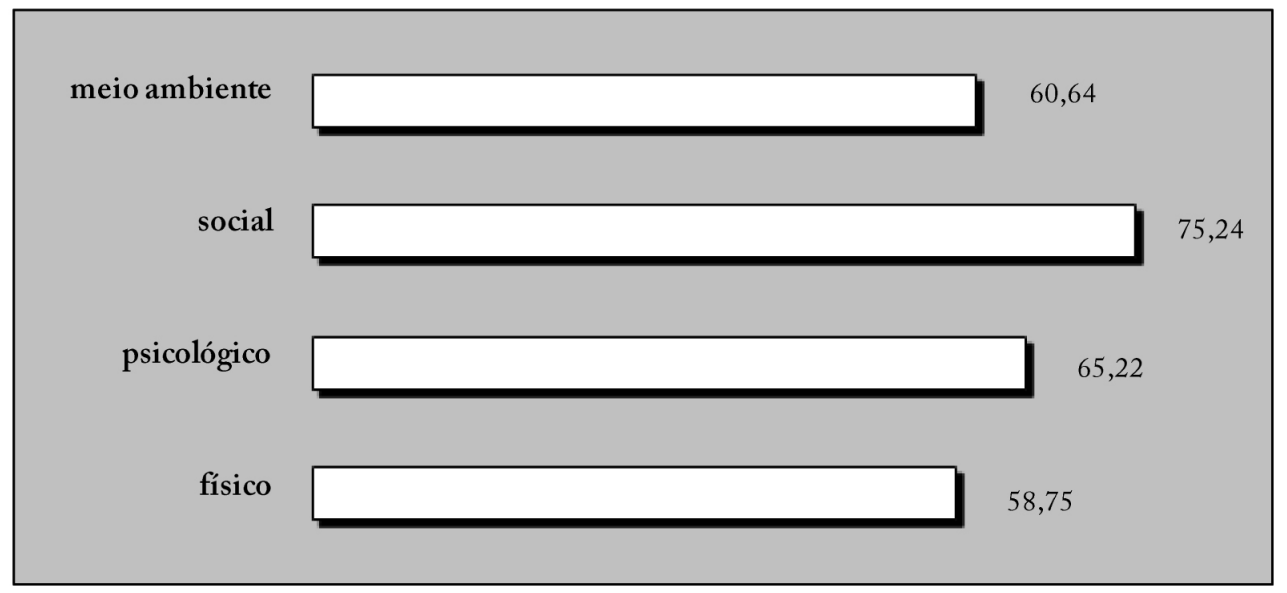

Figura 2 - Pontuação por domínios do nível de qualidade de vida dos professores de Educação Física da Rede Municipal de Ensino de Campo Grande - MS.

A menor pontuação na qualidade de vida no domínio físico pode estar relacionada às características das atribuições profissionais do professor de Educação Física, pois a execução de suas atividades exige que se fique em pé durante toda a aula. Em estudo realizado com operadores de caixa de uma rede de supermercado em Florianópolis SC, Battisti, Guimarães e Simas (2005) também identificaram que a maioria (65\%) dos avaliados sentia desconforto ou dores físicas durante o trabalho, sendo o ato de trabalhar em pé apontado por 39\% como o principal responsável por tais sensações. Souza e Figueiredo (2004), em estudo desenvolvido com profissionais da USP de Ribeirão Preto - SP, também verificaram menor satisfação dos avaliados no domínio físico. De acordo com os autores, os profissionais que apresentaram as necessidades menos satisfeitas no domínio físico desempenhavam atividades de maior esforço físico e mobilidade. No caso dos professores de Educação Física, deve-se considerar, também, que o processo ensino/aprendizagem dos jogos, lutas, danças, ginásticas, esportes, atividades rítmicas e expressivas, entre outros, em sua maioria, necessita de demonstração por parte do professor. Conforme expõe Magill (2002), a forma mais popular de ensinar a execução de uma habilidade motora consiste na demonstração da habilidade e na instrução verbal, sendo a demonstração a forma de comunicação mais comum. 
É preciso considerar, também, que, além de ficar em pé praticamente durante toda a aula e demonstrar os movimentos a serem realizados, o professor de Educação Física, ao se defrontar com a competição sonora, acaba elevando o tom de sua voz; sendo a comunicação oral um recurso importante na relação professor/aluno (PENTEADO, 2007), essa elevação do tom da voz pode resultar em problemas, dentre eles o cansaço (DRAGONE, 2001). Em estudo realizado por Shigunov, Farias e Nascimento (2002), em Florianópolis - SC, os professores de Educação Física da Rede Estadual de Ensino relataram o cansaço e o desgaste físico como principais limitadores de seu trabalho e rendimento.

A sobrecarga de trabalho do docente de Educação Física figura como um fator preditivo para esgotamento profissional (BENEVIDES-PEREIRA, 2002). Pesquisa desenvolvida por Santini e Molina-Neto (2005), com professores de Educação Física residentes em Porto Alegre - RS, apontou a multiplicidade de funções como condição predisponente ao esgotamento profissional.

Já a baixa pontuação no nível de qualidade de vida no domínio ambiente pode estar relacionada às condições de trabalho, porque as questões referentes a esse domínio também versam sobre as condições do ambiente físico (clima, barulhos, poluição e atrativos). Penteado e Bicudo-Pereira (2007), em estudo realizado com professores do Ensino Médio de quatro escolas estaduais de Rio Claro - SP, evidenciaram que o domínio meio ambiente quando comparado aos domínios físico, psicológico e relações sociais, configurava-se como o mais prejudicado. Em relação ao ambiente físico, sabe-se que as condições de trabalho do profissional de Educação Física não são as melhores, uma vez que a exposição ao sol e à poeira é frequente. Além disso, há de considerar que as aulas de Educação Física frequentemente são realizadas em locais abertos, fazendo com que a voz dos professores fique exposta à competição sonora do ambiente. De acordo com Pereira, Santos e Viola (2000), a prática docente em ambientes ruidosos leva os professores a elevar a intensidade da voz devido à competição sonora e à necessidade de superar os ruídos circundantes.

Todavia, não se pode desconsiderar os efeitos de outros aspectos que englobam o domínio meio ambiente, principalmente os relacionados à disponibilização de dinheiro para satisfazer as necessidades e o acesso às oportunidades de atividade de lazer. Em relação à disponibilização de tempo para o lazer, sabe-se que a carreira docente não é uma das mais favoráveis, pois suas atribuições não se limitam ao cumprimento da carga horária semanal no ambiente escolar, porque, frequentemente, professores levam trabalhos para casa (elaboração e correção de trabalhos e avaliações), fazendo com que o tempo disponível para as atividades de lazer seja ainda menor. É preciso considerar ainda que, na Sociedade Contemporânea, muitos trabalhadores buscam auxílio à renda com a realização de outras funções (JUNQUEIRA; MÜLLER, 2002), "vendendo", assim, o tempo disponível que poderia ser usufruído com atividades de lazer.

Embora Cantos (2005) afirme que, devido ao estresse profissional, frequentemente encontramos professores que não se relacionam bem com seus colegas de trabalho, os dados obtidos apresentam indícios dessa condição não ter ocorrido entre professores deste estudo, pois as relações sociais foi o domínio com o resultado mais positivo $-75,24$ pontos. 
Em parte, isso pode ter ocorrido pelo dinamismo e pelo potencial comunicativo característico do profissional de Educação Física e, ainda, pode ser decorrente da empatia dos alunos pela disciplina e, consequentemente, pelos professores, proporcionando, desse modo, uma relação amistosa entre professores e alunos no processo ensino/aprendizagem. Silva e Krug (2007) constataram que a afetividade dos alunos figurava como o fator de maior motivação na prática docente de professores de Educação Física da região central do estado do Rio Grande do Sul (Caçapava do Sul, São Sepé, Santa Maria, Julio de Castilhos e Tupanciretã). Em estudo realizado com alunas de $5^{\mathrm{a}}$ a $8^{\mathrm{a}}$ séries do Ensino Fundamental de duas escolas pública e particular de Lençóis Paulista - SP, Betti e Liz (2003) identificaram que, para 64,9\% delas, as aulas de Educação Física era a que elas mais gostavam. Ainda, Soriano e Winterstein (1998) verificaram que o maior grau de satisfação com a carreira docente foi entre os professores de Educação Física quando comparado aos de Matemática e Português.

$\mathrm{Na}$ análise de correlação entre as variáveis, nenhuma associação estatisticamente significante foi encontrada entre a idade, o tempo de docência e a carga horária semanal de trabalho (CHST), conforme Tabela 1. A ausência de relação estatisticamente significante entre essas variáveis também foi observada em investigações desenvolvidas por Lemos (2007) e Penteado e Bicudo-Pereira (2007).

Tabela 3 - Nível de correlação $\left(r_{s}\right)$ entre o perfil demográfico e profissional e a qualidade de vida total e por domínios

\begin{tabular}{|l|c|c|c|}
\hline \multicolumn{1}{|c|}{ QUALIDADE DE VIDA } & Idade & TD & CHST \\
\hline Geral & 0,054 & $-0,079$ & $-0,002$ \\
\hline Domínio físico & 0,103 & $-0,014$ & $-0,193$ \\
\hline Domínio psicológico & 0,025 & $-0,116$ & $-0,074$ \\
\hline Domínio social & $-0,074$ & $-0,114$ & 0,035 \\
\hline Domínio meio ambiente & 0,008 &,- 206 & $-0,055$ \\
\hline
\end{tabular}

Legenda: TD (Tempo de docência); CHTS (Carga horária semanal de trabalho)

Embora nenhuma relação entre o perfil demográfico e profissional e a qualidade de vida tenha sido identificada, em estudo conduzido por Penteado e Bicudo-Pereira (2007), constatou-se que a carga horária de trabalho correlacionava-se negativamente com a percepção dos professores sobre a qualidade da voz. Desta forma, pode ser que a quantidade de aulas lecionadas aja apenas sobre a qualidade de vida vocal. Possivelmente isso ocorra devido à fala ser um importante recurso no processo ensino/ aprendizagem e pelo fato da docência, muitas vezes, ocorrer em ambientes ruidosos, exigindo que o professor eleve a intensidade vocal para superar o ruído ambiental.

\section{Conclusão}

Este estudo mostra que a maioria dos professores avaliados classifica sua qualidade de vida como "boa", contudo os resultados obtidos nos domínios físico e meio ambiente não foram satisfatórios. Tais resultados devem ser vistos com preocupação 
por parte das autoridades municipais: além de provocar transtornos à saúde do professor, uma má qualidade de vida, pode afetar, ainda, a qualidade do ensino.

Considerando que o profissional de Educação Física Escolar exerce sua profissão em pé e a regência dessa disciplina muitas vezes é feita em condições adversas (tais como exposição ao sol, à poeira, aos locais abertos, a ruídos), torna-se importante tomar providências no sentido de disponibilizar locais de trabalhos mais apropriados para o exercício dessa função.

Embora acreditando que idade, tempo de docência e quantidade de horas aulas ministradas semanalmente influenciassem na qualidade de vida, esses aspectos não foram confirmados no presente estudo. Pode ser que a quantidade de horas semanais exerça mais influência sobre a qualidade de vida vocal que sobre a qualidade de vida geral, conforme evidenciam outros estudos.

\title{
Quality of life, demographic and professional profile of physical education teachers
}

\begin{abstract}
This research study aimed at identifying the demographic and professional profile of physical education teachers as well as associating their life quality level to their age, teaching career length, and their weekly workload. Sixty-nine public school physical education teachers were evaluated in the Brazilian city of Campo Grande, MS. The sample group reached 74.4 points in the general life quality scale, thus indicating a good level of life quality. The social domain, with $75.24 \%$, ranked as the most positive one, while the physical domain, with 58.75 , ranked as the lowest one. Wages were pointed by $66.7 \%$ of subjects as the main cause of professional dissatisfaction. On testing the relation between all evaluated variables, no significant statistical relation was found. Results show that most physical education teachers find their life quality to be good. Demographic and professional profiles did not influence their quality of life.
\end{abstract}

Keywords: Work - Quality of life - Teachers.

\section{Cualidad de vida, perfil demográfico y profesional de profesores de educación física}

\section{Resumen}

El estudio buscó identificar el perfil demográfico y profesional de profesores de Educación Física bien como la asociación entre el nivel de cualidad de vida con la edad, tiempo de docencia y carga horaria semanal de trabajo. Fueron evaluados 69 profesores de Educación Física de escuelas públicas en Campo Grande - MS. En la cualidad de vida general la muestra obtuvo 74,4 puntos, indicando una buena cualidad de vida. En el análisis por dominios, el social $(75,24 \%)$ figuró como lo más positivo y el físico $(58,75$ puntos) el más perjudicado. El sueldo fue apuntado por $66,7 \%$ como el principal factor de insatisfacción profesional. En el teste de relación entre las variables ninguna asociación estadísticamente significante fue encontrada. Se concluye que la mayoría de los profesores clasificó su cualidad de vida como "buena" y que el perfil demográfico y profesional no ejerció influencia sobre la cualidad de vida.

Palabras clave: Trabajo - Calidad de vida - Docente.

\section{Referências}

BATTISTI, H. H.; GUIMARÃES, A. C. A.; SIMAS, J. P. N. Atividade física e qualidade de vida de operadores de caixa de supermercado. Revista Brasileira Ciência E Movimento, Brasília, v. 13, n. 1, p. 71-78, 2005. Disponível em: <http://portalrevistas.ucb.br/index.php/RBCM/article/view/614/626>. Acesso em: 10 out. 2008.

BENEVIDES-PEREIRA, A. M. T. (Org.). Burnout: quando o trabalho ameaça o bem estar do trabalhador. São Paulo: Casa do Psicólogo, 2002. 
BETTI, M.; LIZ, M.T.F. Educação física escolar: a perspectiva de alunas do ensino fundamental. Motriz, Rio Claro, v. 9, n. 3, p. 135-142, set./dez., 2003. Disponível em: <http:// www.rc.unesp.br/ib/efisica/motriz/09n3/08MBetti.pdf>. Acesso em: 15 jul. 2008.

BOTH, J.; NASCIMENTO, J. V.; BORGATTO, A. F. Percep̧̧ão da qualidade de vida no trabalho e perfil do estilo de vida dos docentes de educação física do estado de Santa Catarina. Revista da Educaşão Física/UEM, Maringá, v. 19, n. 3, p. 377-389, jul./set., 2008. Disponível em: <http://dx.doi.org/10.4025/reveducfis.v19i3.5993>. Acesso em: 12 jun. 2009.

CANTOS, G. A. Estresse e seu reflexo na saúde do professor. Revista Brasileira de Análises Clínicas, Piracicaba, v. 7, n. 15, p. 15-20, 2005. Disponível em: $<$ http://www. unimep.br/phpg/editora/revistaspdf/saude15art02.pdf $>$. Acesso em: 26 maio 2008.

DRAGONE, M. L. O. S. Novos caminhos para os estudos sobre a voz do professor. Revista Fonoaudiologia Brasil, v. 1, n. 1, p. 43-50, 2001.

FARIAS, G. O. et al. Carreira docente em educação física: uma abordagem sobre a qualidade de vida no trabalho de professores da rede estadual de ensino do Rio Grande do Sul. R. da Educação Física/UEM, Maringá, v. 19, n. 1, p. 11-22, jan./mar., 2008. Disponível em: <http://www.periodicos.uem.br/ojs/index.php/RevEducFis/article/ view/4310/2912>. Acesso em: $10 \mathrm{dez} .2008$.

FERNANDES, E. Qualidade de vida no trabalho: como medir para melhorar. Salvador: Casa da qualidade de vida, 1996.

FLECK, M. P. A. et al. Aplicação da versão em português do instrumento abreviado de avaliação da qualidade de vida "WHOQOL-bref". Revista Saúde Pública, São Paulo, v. 34, n. 2, p. 178-83, abr., 2000. Disponível em: <http://dx.doi.org/10.1590/ S0034-89102000000200012>. Acesso em: 12 dez. 2008.

FOLLE, A. et al. Carreira no magistério público e nível de qualidade de vida no trabalho docente em educação física. Motriz, Rio Claro, v. 14, n. 3, p. 210-221, jul./ set., 2008. Disponível em: <http://cecemca.rc.unesp.br/ojs/index.php/motriz/article/viewFile/1396/1756>. Acesso em: 11 dez. 2008.

JUNQUEIRA, D. M.; MÜLLER, A. Atividades de lazer dos professores das escolas particulares: um estudo de caso no município de Taquari - RS. Cinergis, Santa Cruz do Sul, v. 3, n. 2, p. 111-140, 2002.

LAPO, F. R. Professores retirantes: um estudo sobre a evasão docente no magistério público do estado de São Paulo (1990-1995). In: REUNIÃO ANUAL DA ANPED, 23., 2000, Caxambu. Anais... Caxambu: ANPED, 2000, v. 1, p. 34-49.

LEGNANI, E. et al. Perception of the quality of life in the work of teachers' university students of physical education ef different exes curriculares. Fiep Bulletin, Foz do Iguaçu, v. 75, n. especial, p. 425-427, jan., 2005.

LEMOS, C. A. F. Qualidade de vida na carreira profissional de professores de educação fisisica do magistério público estadual do Rio Grande do Sul. 2007. xx f. Dissertação (Mestrado em Educação Física) - Curso de Educação Física, UFSC, Florianópolis, 2007. 
LEMOS, C. A. F.; NASCIMENTO, J. V.; BOTH, J. Qualidade de vida no trabalho percebida por professores de educação física. In: FÓRUM INTERNACIONAL INTEGRADO DE CIDADANIA: EDUCAÇÃO, CULTURA, SAÚDE E MEIO AMBIENTE, 2006, Santo Ângelo - RS. Anais... Santo Ângelo-RS, 2006, v. 1, p. 68-88.

MAGILL, R. A. Aprendizagem motora: conceitos e aplicações. 5 ed. São Paulo: Edgard Blücher Ltda, 2002.

MARCONI, M. A.; LAKATOS, E. M. Técnicas de pesquisa. 5 ed. São Paulo: Atlas, 2002.

MASLACH, C.; LEITER, M. P. Trabalho: fonte de prazer ou desgaste? Guia para vencer o estresse na empresa. Campinas, SP: Papirus, 1999.

MELEIRO, A. M. A. S. O stress do professor. In: LIPP, M. E. N. (Org.). O stress do professor. Campinas-SP: Papirus, 2002. p. 11-27.

MOLINA, O. F. Estresse no cotidiano. Santa Célia - SP: Pancast, 1996.

NUNES SOBRINHO, F. P. O stress do professor do ensino fundamental: o enfoque da ergonomia. In: LIPP, M. E. N. (Org.). O stress do professor. Campinas: Papirus, 2002. p. 81-94.

OLIVEIRA, S. L. Tratado de metodologia cientifica. 2 ed. São Paulo, SP: Pioneira, 2002.

PENTEADO, R. Z. Relações entre saúde e trabalho docente: percepções de professores sobre a saúde vocal. Revista Sociedade Brasisleira de Fonoaudiologia, São Paulo, v. 12, n. 1, p. 18-22, jan./mar., 2007. Disponível em: <http://www.scielo.br/pdf/rsbf/ v12n1/03.pdf>. . Acesso em: 15 maio 2008.

PENTEADO, R. Z.; BICUDO-PEREIRA, I. M. T. Qualidade de vida e saúde vocal de professores. Revista de Saúde Pública, Rio Claro, v. 41, n. 2, p. 236-243, 2007. Disponível em: <http://dx.doi.org/10.1590/S0034-89102007000200010>. Acesso em: 11 jan. 2008.

PEREIRA, M. J.; SANTOS, T.M.M.; VIOLA, I.C. Influência do nível de ruído em sala de aula sobre a performance vocal do professor. In: FERREIRA, L. P.; COSTA, H. O. Voz ativa: falando sobre o profissional da voz. São Paulo: Roca, 2000. p. 57-65.

PETROSKI, E. C. Qualidade de vida no trabalho e suas relaçôes com estresse, nivel de atividade física e risco coronariano de professores universitários. 2005. xx f. Tese (Doutorado em Engenharia de Produção), UFSC, Florianópolis, 2005.

ROMANZINI, M. et al. Quality of life perception at work by physical education university teachers according to the professional development cycle. Fiep Bulletin, Foz do Iguaçu, v. 75, n. especial, p. 565-570, jan., 2005.

SALIM, N. A. O estresse relacionado aos professores de educação física escolar. 2004. xx f. Monografia (Licenciatura em Educação Física) - Curso de Educação Física, UCDB, Campo Grande, 2004. 
SANTINI, J.; MOLINA NETO, V. A síndrome do esgotamento profissional em professores de educação física: um estudo na rede municipal de ensino de Porto Alegre. Revista Brasileira de Educaşão Física e Esportes, São Paulo, v. 19, n. 3, p. 209-222, jul./set., 2005. Disponível em:<http://www.usp.br/eef/rbefe/v19n32005/v19n3p209. pdf $>$. Acesso em: 23 set. 2008.

SHIGUNOV, V.; FARIAS, G. O.; NASCIMENTO, J. V. O percurso profissional dos professores de educação física nas escolas. In: SHIGUNOV NETO, A.; SHIGUNOV, V. (Org.). Educaşão física: conhecimentos teórico x prática pedagógica. Porto Alegre: Mediação, 2002. p. 19-53.

SILVA, M. S.; KRUG, H. N. Os sentimentos satisfação e insatisfação dos professores de educação física. Revista Digital, Buenos Aires, ano 12, n. 115, p. s/n, 2007. Disponível em: <http://www.efdeportes.com/efd115/satisfacao-e-insatisfacao-dosprofessores-de-educacao-fisica.htm>. Acesso em: 18 set. 2008.

SORIANO, J. B.; WINTERSTEIN, P. J. Satisfação no trabalho do professor de educação física. Revista Paulista de Educação Física, São Paulo, v. 12, n. 2, p. 145-159, jul./dez., 1998. Disponível em: <http://www.usp.br/eef/rpef/v12n2/v12n2p145. pdf>. Acesso em: 23 abr. 2008.

SOUZA, L. B.; FIGUEIREDO, M. A. C. Qualificação profissional e representações sobre trabalho e qualidade de vida. Paidéia: cadernos de psicologia e educação, Ribeirão Preto, v. 14, n. 28, p. 221-232, 2004. Disponível em: <http://sites.ffclrp.usp.br/ paideia/artigos/28/10.htm>. Acesso em: 13 maio 2008.

THE WHOQOL GROUP. Development of the world. Health Organization WHOQOL-bref. Quality of life assessment 1998. Psychol Med., v. 28, p. 551-558, may., 1998. Disponível em: <http://www.ncbi.nlm.nih.gov/pubmed/9626712>. Acesso em: 24 ago. 2008.

THOMAS, J. R.; NELSON, J. K. Métodos de pesquisa em atividade fisica. 3 ed. Porto Alegre: Artmed, 2002.

TRICOLLI, V. A. C. Sintomas de stress em escolares de $1^{a}$ a a $4^{a}$ série. 1997. 123 f. Dissertação (Mestrado em Psicologia) - Departamento de pós-graduação em Psicologia Clínica, PUC, Campinas, 2007.

Recebido em: 17 de abril de 2008

Revisado em: 21 de julho de 2009

Aprovado em: 10 de agosto de 2009

Endereço para correspondência

jr_lazer@yahoo.com.br

Junior Vagner Pereira da Silva

Universidade para o Desenvolvimento do Estado e da Região do Pantanal

Rua Ceará, 333 - Bloco V - Bairro Miguel Couto - Campo Grande - MS

CEP 79003-010 